\title{
Endocapillary Proliferation was Associated with Unfavorable Outcomes in Children with Henoch- Schönlein Purpura Nephritis and IgA Nephropathy
}

\section{Supatjaree Chanvitan}

Mahidol University Faculty of Medicine Ramathibodi Hospital

Kanchana Tangnararatchakit

Mahidol University Faculty of Medicine Ramathibodi Hospital

\section{Pawaree Saisawat}

Mahidol University Faculty of Medicine Ramathibodi Hospital

\section{Songkiat Chantarogh}

Mahidol University Faculty of Medicine Ramathibodi Hospital

\section{Suchin Worawichawong}

Mahidol University Faculty of Medicine Ramathibodi Hospital

\section{Kwanchai Pirojsakul ( $\square$ Kwanchai.pio@mahidol.ac.th )}

Mahidol University Faculty of Medicine Ramathibodi Hospital https://orcid.org/0000-0002-9043-6689

\section{Research article}

Keywords: Henoch-Schönlein purpura, IgA nephropathy, Endocapillary proliferation, Outcomes, Prognosis, Children

Posted Date: July 7th, 2020

DOl: https://doi.org/10.21203/rs.3.rs-39010/v1

License: (c) (1) This work is licensed under a Creative Commons Attribution 4.0 International License. Read Full License 


\section{Abstract}

Introduction: There are limited data on the outcomes in children with Henoch-Schönlein purpura nephritis (HSPN) and IgA nephropathy (IgAN) in limited-resource countries. This study was aimed to evaluate the outcome of HSPN and IgAN and to evaluate the pathological findings associated with unfavorable outcomes.

Materials and methods: This was a retrospective study conducted in children ( $\leq 18$ years) diagnosed with HSPN or IgAN, had estimated glomerular filtration rate (eGFR) $\geq 60 \mathrm{~mL} / \mathrm{min} / 1.73 \mathrm{~m}^{2}$ and underwent renal biopsy between year 2002 - 2018 at Ramathibodi Hospital, Bangkok, Thailand. Clinical outcomes were graded according to the outcome classification by Counahan, as follows: favorable [A, normal; $B$, minor urinary abnormalities (proteinuria $<1 \mathrm{~g} / 1.73 \mathrm{~m}^{2} /$ day)]; unfavorable $[\mathrm{C}$, active renal disease (proteinuria $>1 \mathrm{~g} / 1.73 \mathrm{~m}^{2} /$ day and/or hypertension); D, renal insufficiency (eGFR $<60 \mathrm{~mL} / \mathrm{min} / 1.73 \mathrm{~m}^{2}$ or died)]. Pathologies were graded according to Oxford classification.

Results: A total of 47 patients ( 28 HSPN and $19 \mathrm{lgAN}$ ) were included with means of age at $9.4 \pm 2.8 \mathrm{vs}$ $11.3 \pm 4.3$ years, respectively. After a median follow-up time of 50 months, proportions of favorable outcomes in the patients with HSPN and IgAN were $82.1 \%(23 / 28)$ and $89.5 \%(17 / 19)$, respectively ( $p$ value $=0.685)$. In multivariate analysis, only endocapillary proliferation $(E)$ was associated with unfavorable outcomes in both diseases with the odds ratio $(95 \% \mathrm{Cl})$ of $12.46(1.36-114.51, p$-value $=$ 0.026).

Conclusion: The clinical outcomes of most patients with HSPN and IgAN were favorable and comparable. Endocapillary proliferation $(E)$ was the only factor associated with poor outcome in both diseases.

\section{Introduction}

Immunoglobulin A nephropathy (IgAN) and Henoch-Schönlein purpura nephritis (HSPN) are common glomerular diseases in children. HSPN usually presents with involvement of skin, joints and gastrointestinal tract and approximately $20-47 \%$ of patients had renal involvement (e.g. proteinuria, hematuria $)^{1-3}$. However, IgAN usually presents with renal limited symptoms such as recurrent hematuria or proteinuria in which diagnosis needs to be confirmed by renal pathology showing mesangial deposition of IgA in glomeruli. Both diseases share common clinical features and pathologies ${ }^{2}$. The clinical, genetic and immunologic features of these conditions are so closely linked that one could consider HSPN as a systemic form of IgAN ${ }^{4-6}$. The pathogenesis of both conditions are proposed to be related with galactose-deficiency of O-linked glycans in the hinge region of IgA1 subtype. These structures are recognized by autoantibodies, resulting in the formation of immune complexes in the circulation and deposition of these immune complexes in various organs ${ }^{5,7-9}$.

In IgAN, the previous studies in pediatric patients indicated that 5-year and 20-year renal survival rates were $94-100 \%$ and $70-89 \%$, respectively ${ }^{10-14}$. Several factors have impact on the prognosis in patients 
with IgAN, such as elevated serum creatinine, heavy proteinuria, and hypertension ${ }^{15}$. However, the outcome of IgAN in children is generally a complete resolution of clinical signs and symptoms ${ }^{4,13,14}$. Children with IgAN who have a normal urinalysis after treatment usually do not progress to end-stage renal disease (ESRD) ${ }^{4}$. In HSPN, mild cases usually show a complete resolution of nephritis. However, some studies reported the recurrence rate between $2.7-30 \%^{16-18}$. Data from unselected cohorts showed that 5-year renal survival rates were between $82-95 \%{ }^{19-21}$. The unfavorable prognosis of HSPN usually links to severe clinical symptoms or pathology at the initial presentation. There are several studies regarding the outcomes of treatment and pathological findings in adults with IgAN and HSPN. However, there are limited data on pathological findings and outcomes of treatment in children in Thailand. The aims of this study were to evaluate the outcomes of HSPN and IgAN and to evaluate the pathological findings associated with unfavorable outcomes.

\section{Materials And Methods}

We performed a retrospective single-center study by reviewing the medical records and renal biopsy results of children aged $\leq 18$ years, diagnosed with HSPN or IgAN from years 1998-2018 at Ramathibodi Hospital, Bangkok, Thailand. HSPN was diagnosed according to criteria defined by the American College of Rheumatology ${ }^{1}$. IgAN was diagnosed based on the results of pathology findings without the presence of extrarenal symptoms at initial diagnosis and during the follow-up period. Secondary IgAN, eg. liver disease, inflammatory bowel disease and infection-induced IgAN were excluded. All medical records were reviewed with emphasis on baseline characteristics, clinical presentation, laboratory data, pathological findings, treatments, and outcomes. Ethical permission was obtained from the Ethics Committee in Human Research of the Faculty of Medicine, Ramathibodi Hospital (ID 09-61-59 for IgAN and ID 09-61-29 for HSPN).

Hypertension was diagnosed if blood pressure (BP) $\geq$ the 95th percentile for age, gender and height on repeated measurements ${ }^{22}$. Proteinuria was defined as a positive protein in urine dipstick testing or urine protein-to-creatinine ratio (UPCr) $\geq 0.2 \mathrm{~g} / \mathrm{g}$. Hematuria was defined as positive blood in urine dipstick testing or $\geq 5$ red blood cells per high-power on microscopic examination of a centrifuged urine specimen. Estimated glomerular filtration rate (eGFR) was calculated by the bedside CKiD equation as follows ${ }^{23}$ :

eGFR $=0.413 \times$ height $(\mathrm{cm}) /$ serum creatinine $(\mathrm{mg} / \mathrm{dl})$

All renal biopsies were performed prior to the initiation of treatment and reviewed by the two experienced renal histopathologists. Stains used for assessment were H\&E, PAS, Jones and Masson's trichrome. All specimens were examined by light microscopy, immunofluorescence staining and electron microscopy. MEST-C criteria in the updated Oxford classification were used to describe pathological data which were standardized for classification in IgA nephropathy ${ }^{24}$. The MEST-C criteria comprise of mesangial hypercellularity (with $\mathrm{M} 0$ and $\mathrm{M} 1$ ) corresponding to $\leq 50 \%$ and $>50 \%$ of the glomeruli showing 
hypercellularity, respectively), endocapillary proliferation (defined as E0, absence or E1, presence), segmental glomerulosclerosis (defined as S0, absence or S1, presence), tubular atrophy/interstitial fibrosis (with T0, T1, and T2 corresponding to $\leq 25 \%, 26 \%-50 \%$, and $>50 \%$ of cortical area involvement, respectively), cellular/fibrocellular crescents (with $\mathrm{C} 0, \mathrm{C} 1$, and $\mathrm{C} 2$ corresponding to their absence, presence in $\geq 1$ and $<25 \%$ of glomeruli, and presence in $\geq 25 \%$ of the glomeruli, respectively). This classification has been validated for use in HSPN in previous adults and pediatric studies ${ }^{25,26}$. However, patients who had missing data, no glomerulus presented in the renal biopsy specimens or an initial eGFR $<60 \mathrm{~mL} / \mathrm{min} / 1.73 \mathrm{~m}^{2}$ were excluded.

The treatment regimen was decided by the attending nephrologists at the time of consultation. Patients who had proteinuria with or without microscopic hematuria received enalapril with the doses ranging from $0.1-0.6 \mathrm{mg} / \mathrm{kg} / \mathrm{day}$. If nephrotic-range proteinuria was detected, corticosteroid therapy (prednisolone or intravenous methylprednisolone) was prescribed with the maximum dose of $2 \mathrm{mg} / \mathrm{kg} /$ day or not exceeding $60 \mathrm{mg} /$ day. Immunosuppressive agents were also prescribed in corticosteroid-resistant cases.

Clinical outcomes were graded according to the outcome classification by Counahan ${ }^{27}$, as follows: A, normal (normal physical examination with normal urine and renal function); $B$, minor urinary abnormalities (proteinuria $<1 \mathrm{~g} / 1.73 \mathrm{~m}^{2} /$ day with or without microscopic); C, active renal disease (proteinuria $>1 \mathrm{~g} / 1.73 \mathrm{~m}^{2} /$ day and/or hypertension); D, renal insufficiency (eGFR $<60 \mathrm{~mL} / \mathrm{min} / 1.73 \mathrm{~m}^{2}$ or died). However, some patients who had no 24-hour urine collection at the last follow up visit, we used protein-to-creatinine ratio $>1 \mathrm{~g} / \mathrm{g}$ instead of $1 \mathrm{~g} / 1.73 / \mathrm{m}^{2} /$ day. Outcome $A$ or B were considered as a favorable outcome and outcome $\mathrm{C}$ or $\mathrm{D}$ were considered as an unfavorable outcome.

The IBM SPSS program version 24 was used for analysis. Data were presented as percentages, mean and standard deviation or median and interquartile range (IQR), as appropriate. Categorical data and proportions were compared using Chi-square test or Fisher's exact test, as appropriate. Student's t-test or Mann-Whitney $\mathrm{U}$ test was used for comparison of continuous data between the two groups, as appropriate. Bivariate logistic regression analysis was used to identify the factors associated with the unfavorable outcome. A $p$-value of less than 0.05 was considered statistically significant.

\section{Results}

\section{Baseline characteristics and pathological findings}

A total of 75 patients diagnosed with HSPN and IgAN over a 17-year period were reviewed. Twenty-eight patients were excluded from the study due to no renal pathological data or no glomerular presented in the specimen (14), missing data (3) and eGFR $<60 \mathrm{ml} / \mathrm{min} / 1.73 \mathrm{~m}^{2}$ (10 from IgAN, 1 from HSPN). Therefore, 28 patients ( 16 males) with HSPN and 19 (12 males) with IgAN were included in the final analysis. The demographic, clinical, and pathological data are summarized in Table 1. The median number of glomeruli from the renal biopsies was 14 glomeruli ranging from 5 to 44 glomeruli. 
Table 1

Baseline characteristics, clinical presentation and renal pathological findings of groups of patients with HSPN and IgAN

\begin{tabular}{|c|c|c|c|}
\hline Characteristics & $\begin{array}{l}\text { HSPN } \\
(N=28)\end{array}$ & $\begin{array}{l}\lg A N \\
(N=19)\end{array}$ & $p$-value \\
\hline Age (years), mean $\pm S D$ & $9.4 \pm 2.8$ & $11.3 \pm 4.3$ & 0.078 \\
\hline Male, n (\%) & $16(57.1)$ & $12(63.2)$ & 0.680 \\
\hline Weight z-score, median (IQR) & $0.20(-0.61-1.18)$ & $0.36(-0.91-1.59)$ & 0.991 \\
\hline Height z-score, median (IQR) & $0.20(-0.30-1.18)$ & $0.20(-1.70-1.30)$ & 0.594 \\
\hline BMI $\left(\mathrm{kg} / \mathrm{m}^{2}\right)$, median (IQR) & $16.8(14.3-21.0)$ & $17.2(16.0-19.8)$ & 0.467 \\
\hline Percentile of systolic BP, mean \pm SD & $83.9 \pm 13.0$ & $78.1 \pm 23.0$ & 0.272 \\
\hline Percentile of diastolic BP, mean \pm SD & $79.9 \pm 19.8$ & $79.1 \pm 25.1$ & 0.903 \\
\hline \multicolumn{4}{|l|}{ Initial investigation } \\
\hline Serum sodium $(\mathrm{mmol} / \mathrm{L})$, mean $\pm \mathrm{SD}$ & $137.5 \pm 3.2$ & $138.0 \pm 2.6$ & 0.599 \\
\hline eGFR $\left(\mathrm{mL} / \mathrm{min} / 1.73 \mathrm{~m}^{2}\right)$, mean $\pm \mathrm{SD}$ & $123.0 \pm 32.1$ & $111.2 \pm 30.1$ & 0.214 \\
\hline Albumin $(\mathrm{g} / \mathrm{L})$, mean $\pm \mathrm{SD}$ & $30.3 \pm 6.1$ & $34.2 \pm 7.4$ & 0.052 \\
\hline UPCr (g/g), median (IQR) & $4.5(2.0-5.7)$ & $2.0(0.9-7.2)$ & 0.270 \\
\hline \multicolumn{4}{|l|}{ Clinical presentation, n (\%) } \\
\hline Edema & $10(35.7)$ & $6(31.6)$ & 0.769 \\
\hline Hypertension & $8(28.6)$ & $3(15.8)$ & 0.485 \\
\hline Acute kidney injury & $1(3.6)$ & $1(5.3)$ & 1.000 \\
\hline Microscopic hematuria & $18(64.3)$ & $3(15.8)$ & 0.001 \\
\hline Gross hematuria & $10(35.7)$ & $16(84.2)$ & 0.001 \\
\hline Proteinuria & $27(96.4)$ & $19(100)$ & 1.000 \\
\hline Nephrotic-range proteinuria & $21(75.0)$ & $8(42.1)$ & 0.023 \\
\hline \multicolumn{4}{|l|}{ Renal pathological findings } \\
\hline Total glomeruli, median (IQR) & $14(9.3-23.5)$ & $14(11.0-20.0)$ & 0.965 \\
\hline Crescent $(\mathrm{C} 1+\mathrm{C} 2), \mathrm{n}(\%)$ & $10(35.7)$ & $2(10.5)$ & 0.052 \\
\hline
\end{tabular}

$\mathrm{BMI}$, body mass index; eGFR, estimated glomerular filtration rate; UPCr, urine protein to creatinine ratio; $M$, mesangial hypercellularity; $E$, endocapillary proliferation; $S$, segmental glomerulosclerosis; $T$, tubular atrophy/interstitial fibrosis; C, cellular/fibrocellular crescents 


\begin{tabular}{|c|c|c|c|}
\hline Characteristics & $\begin{array}{l}\text { HSPN } \\
(N=28)\end{array}$ & $\begin{array}{l}\operatorname{IgAN} \\
(N=19)\end{array}$ & $p$-value \\
\hline Segmental sclerosis (S1), n (\%) & $13(46.5)$ & $9(47.4)$ & 0.949 \\
\hline $\begin{array}{l}\text { Tubular atrophy/interstitial disease }(\mathrm{T} 1+\mathrm{T} 2) \text {, } \\
\mathrm{n}(\%)\end{array}$ & $5(17.9)$ & $6(31.6)$ & 0.312 \\
\hline Endocapillary proliferation (E1), n (\%) & $11(39.9)$ & $8(42.1)$ & 0.847 \\
\hline Mesangial hypercellularity (M1), n (\%) & $8(28.5)$ & $5(26.3)$ & 0.865 \\
\hline \multicolumn{4}{|c|}{$\begin{array}{l}\text { BMI, body mass index; eGFR, estimated glomerular filtration rate; UPCr, urine protein to creatinine } \\
\text { ratio; M, mesangial hypercellularity; } E \text {, endocapillary proliferation; } \mathrm{S} \text {, segmental glomerulosclerosis; } \mathrm{T} \text {, } \\
\text { tubular atrophy/interstitial fibrosis; } \mathrm{C} \text {, cellular/fibrocellular crescents }\end{array}$} \\
\hline
\end{tabular}

\section{Treatment}

Corticosteroids, immunosuppressive agents, and ACEls and/or ARBs were usually prescribed in both groups. The proportion of patients receiving corticosteroids were higher in HSPN compared to IgAN ( $96.4 \%$ vs $63.2 \%, p=0.003$ ) but the proportion of patients receiving cyclophosphamide, cyclosporine, azathioprine, ACEls and/or ARBs were not significantly different between the two groups.

\section{Outcomes}

Medians of follow-up duration were 50.4 (20.5-100.1) months in the HSPN group and 49.2 (25.6-105.2) months in the IgAN group. The outcomes of both diseases are shown in Table 2. There was no significant difference in the proportion of patients who had remission of proteinuria in HSPN vs IgAN $(89.3 \%$ vs $73.7 \%)$, presence of hematuria ( $28.6 \%$ vs $31.6 \%)$, and presence of hypertension at last visit $(10.3 \%$ vs $20.7 \%)$. Outcome A or B was seen in $23 / 28(82.1 \%)$ in HSPN, and $17 / 19(89.5 \%)$ in IgAN $(p=0.685)$. None of the patients in either group had developed ESRD, required renal replacement therapy or died at the last follow-up. 
Table 2

Treatment, complication, and outcome of HSPN and IgAN

\begin{tabular}{|llll|}
\hline & HSPN & IgAN & p-value \\
\hline Treatment & $(\mathbf{N = 2 8 )}$ & $(\mathbf{N = 1 9 )}$ & \\
\hline Steroids, $\mathrm{n}(\%)$ & & & \\
\hline Cy, $\mathrm{n}(\%)$ & $27(96.4)$ & $72(63.2)$ & 0.003 \\
\hline Cy accumulation dose (mg/kg/day) & $17(60.7)$ & $7(36.8)$ & 0.108 \\
\hline ACEls and/or ARBs, $\mathrm{n}(\%)$ & $138.5 \pm 44.6$ & $129.8 \pm 31.7$ & 0.647 \\
\hline Cyclosporine, $\mathrm{n}(\%)$ & $24(85.7)$ & $15(78.9)$ & 0.697 \\
\hline Azathioprine, $\mathrm{n}(\%)$ & $0(0)$ & $1(5.3)$ & 0.404 \\
\hline Outcome & $2(7.1)$ & $2(10.5)$ & 1.000 \\
\hline Duration of follow in months, median (IQR) & $50.4(20.5-100.1)$ & $49.2(25.6-105.2)$ & 0.461 \\
\hline Remission of proteinuria, $\mathrm{n}(\%)$ & $25(89.3)$ & $14(73.7)$ & 0.240 \\
\hline Presence of hematuria at last visit, $\mathrm{n}(\%)$ & $8(28.6)$ & $6(31.6)$ & 0.825 \\
\hline Hypertension, $\mathrm{n}(\%)$ & $3(10.3)$ & $6(20.7)$ & 0.470 \\
\hline Last eGFR (mL/min/1.73 m²), mean \pm SD & $115.9 \pm 24.7$ & $118.2 \pm 22.5$ & 0.748 \\
\hline Last UPCr (g/g), median (IQR) & $0.20(0.19-0.87)$ & $0.20(0.18-0.88)$ & 0.692 \\
\hline Last serum albumin (g/L), median \pm SD & $35.6 \pm 6.4$ & $41.7 \pm 5.5$ & 0.012 \\
\hline Outcome A or B, $\mathrm{n}$ (\%) & $23(82.1)$ & $17(89.5)$ & 0.685 \\
\hline $\begin{array}{l}\text { Cy, cyclophosphamide; CMV, cytomegalovirus; } \\
\text { protein to creatinine ratio. }\end{array}$ & & & \\
\hline
\end{tabular}

\section{Factors associated with unfavorable outcome}

Possible risk factors associated with an unfavorable outcome such as gender, age, hypertension, initial acute kidney injury, diagnosis of HSPN or IgAN and pathological findings are presented in Table 3. In univariate analysis, the only factor associated with unfavorable outcome was the presence of endocapillary proliferation (E1) in the initial renal biopsy. Initial eGFR and acute kidney injury tended to be associated with unfavorable outcome $(p<0.3)$. In multivariate analysis, we selected the presence of endocapillary proliferation and AKI in the analysis, E1 remained the only factor associated with outcome C or D with the odds ratios $(95 \% \mathrm{Cl})$ of 9.96 compared to E0 $(1.05-94.80, p=0.046)$ as shown in Table 4. 
Table 3

Factors associated with unfavorable outcome

\begin{tabular}{|c|c|c|c|}
\hline Characteristic & $\begin{array}{l}\text { Favorable } \\
\text { outcome (A, } \\
\text { B) } \\
(N=40)\end{array}$ & $\begin{array}{l}\text { Unfavorable outcome (C, } \\
\text { D) } \\
(N=7)\end{array}$ & $\begin{array}{l}p \\
\text { value }\end{array}$ \\
\hline Male, n (\%) & $23(57.5)$ & $5(71.4)$ & 0.685 \\
\hline Age (years), mean $\pm S D$ & $10.3 \pm 3.7$ & $9.2 \pm 4.1$ & 0.436 \\
\hline Hypertension (mmHg), n (\%) & $8(20.0)$ & $3(42.9)$ & 0.330 \\
\hline Initial albumin $(\mathrm{g} / \mathrm{L})$, mean $\pm \mathrm{SD}$ & $31.4 \pm 7.1$ & $30.5 \pm 6.5$ & 0.554 \\
\hline Initial eGFR $\left(\mathrm{mL} / \mathrm{min} / 1.73 \mathrm{~m}^{2}\right)$, mean $\pm \mathrm{SD}$ & $119.5 \pm 33.8$ & $100.8 \pm 13.0$ & 0.107 \\
\hline Initial UPCr (g/g), median (IQR) & $3.5(1.7-6.6)$ & $2.8(2.1-7.0)$ & 0.723 \\
\hline Diagnosis of HSPN, n (\%) & $23(57.5)$ & $5(71.4)$ & 0.685 \\
\hline Acute kidney injury, n (\%) & $1(2.5)$ & $1(14.3)$ & 0.278 \\
\hline Nephrotic-range proteinuria, $\mathrm{n}(\%)$ & $24(60.0)$ & $5(71.4)$ & 0.692 \\
\hline Crescent $(\mathrm{C} 1+2), \mathrm{n}(\%)$ & $11(27.5)$ & $1(14.3)$ & 0.659 \\
\hline Endocapillary proliferation (E1), n (\%) & $13(32.5)$ & $6(85.7)$ & 0.008 \\
\hline $\begin{array}{l}\text { Tubular atrophy/interstitial fibrosis }(\mathrm{T} 1+2), \mathrm{n} \\
(\%)\end{array}$ & $9(22.5)$ & $2(28.6)$ & 0.659 \\
\hline Segmental sclerosis (S1), n (\%) & $19(47.5)$ & $3(42.9)$ & 1.000 \\
\hline
\end{tabular}

Table 4

Univariate and multivariate analyses of factor associated with unfavorable outcome

\begin{tabular}{|lllll|}
\hline Factors & $\begin{array}{l}\text { Univariate model } \\
\mathrm{HR}(95 \% \mathrm{Cl})\end{array}$ & $\boldsymbol{p}$-value & $\begin{array}{l}\text { Multivariate model } \\
\boldsymbol{\beta}(95 \% \mathrm{Cl})\end{array}$ & $\boldsymbol{p}$-value \\
\hline Endocapillary proliferation & 12.46 & 0.026 & 9.96 & 0.046 \\
& $(1.36-114.51)$ & & $(1.05-94.80)$ & \\
\hline Initial eGFR & $0.97(0.94-1.01)$ & 0.123 & $0.98(0.95-1.02)$ & 0.282 \\
\hline AKI & $6.50(0.36-118.4)$ & 0.206 & & \\
\hline eGFR, estimated glomerular filtration rate; AKI, Acute kidney injury & \\
\hline
\end{tabular}




\section{Discussion}

In this study, the factor associated with an unfavorable outcome (C or D) in HSPN and IgAN was the presence of endocapillary proliferation in the initial renal biopsy with the odds ratios $(95 \% \mathrm{Cl})$ of 12.46 compared to E0 (1.36-114.51, $p=0.026)$. In this regard, Yang et al. reported that endocapillary proliferation was an independent pathological factor in children with HSPN presenting with nephroticrange proteinuria but it did not correlate with the outcome $C$ or $D$ during a follow-up period of 1-4 years $^{28}$. However, recent publication by Inagaki et al. found that $E$ was significantly associated with renal outcome in adult patients with HSPN. It showed that event-free renal survival was significantly shorter in patients with endocapillary proliferation than without endocapillary proliferation $(p=0.0072)^{29}$. In IgAN, Halling et al. found that endocapillary proliferation was a significant predictor of poor outcome in children with IgAN and it could predict the composite endpoint of progression to ESRD or reduction of eGFR. In addition, the latter study also found that mesangial hypercellularity, tubular atrophy/interstitial fibrosis and crescents but not segmental sclerosis, were significant predictors for poor outcome ${ }^{11}$. Although a systematic review and meta-analysis of 16 retrospective cohort studies with $3893 \mathrm{IgAN}$ patients and found that endocapillary proliferation was not associated with renal failure [HR $1.4(95 \% \mathrm{Cl}$ $0.9-2.0), p=0.1]^{30}$, there were only four studies that included children under 18 years of age and the population included all stages of chronic kidney disease.

In the present study, the baseline characteristics of both groups were similar except for the clinical presentation of hematuria and nephrotic-range proteinuria. As IgAN is renal limited disease, patients usually present with gross hematuria, which is self-detectable and brings the patients to the hospital. However, microscopic hematuria was found incidentally in some patients (15.8\%). Apart from hematuria, a larger proportion of patients with HSPN than IgAN had nephrotic-range proteinuria. As HSPN patients were usually diagnosed by skin manifestation and other systemic organ involvement, a renal biopsy was performed only in those patients with HSPN who presented with a significant amount of proteinuria. Therefore, HSPN patients in this study tended to receive corticosteroids more than IgAN due to having significant proteinuria or nephrotic-range proteinuria $(p=0.003)$.

After treatment, the outcomes of both diseases were not significantly different. None of the patients with HSPN or IgAN required renal replacement therapy or died during the medians follow-up time of 50.4 (20.5100.1) and 49.2 (25.6-105.2) months, respectively. Outcomes A or B in this study, considered as a favorable outcome, was found in 23/28 (82.1\%) patients with HSPN and 17/19 (89.5\%) patients with $\lg$ AN $(p=0.685)$. Compared to other studies, Kawasaki et al. investigated 114 HSPN children with renal failure during an average observation period of 23 years and reported that $82.5 \%$ had favorable outcomes after treatment ${ }^{8}$. Goldstein et al. studied 78 HSPN patients during a median follow-up time of 23.4 (1935.1 ) years; showed that outcomes A or B were $64 / 78$ (82.1\%) in 1971 and $56 / 78$ (71.8\%) in $1990^{31}$. Fu et al. also reported that there were $148 / 159(93.1 \%)$ of patients who had normal or mildly abnormal urinary finding (outcomes A or B) after treatment during a follow up period 6 months to 14 years. The latter study also found the association of higher pathological grading with unfavorable outcomes ${ }^{32}$. Mir et al. 
followed 141 HSPN children, and showed outcomes A or B in up to $90.2 \%$ with 1-year follow-up. Nephrotic and/or nephritic syndrome were found to be an unfavorable predictor for both short and long-term outcomes $(p<0.05)^{33}$. In IgAN, Bulut IK et al. studied 29 children included some patients with renal failure during mean follow-up time of $10.4 \pm 3.51$ years and reported that $84.6 \%$ had outcomes $A$ or $B^{34}$. All of these studies showed that the overall prognosis of both diseases in general was comparable and had a good prognosis consistent with our findings.

This study had some limitations. Firstly, it was a retrospective study with a limited number of cases and a short duration of follow-up. Secondly, some other factors could affect the outcome such as different regimens of treatment, different baseline characteristics and different severities of pathological findings. Therefore, further studies with more cases, subgroup analysis, and longer follow-up time are warranted. In conclusion, the clinical outcomes of most pediatric patients with HSPN and IgAN were favorable and comparable. The presence of endocapillary proliferation in the initial renal biopsy was the only independent factor associated with poor outcomes in both diseases.

\section{Declaration Section}

Ethical permission was obtained from the Ethics Committee in Human Research of the Faculty of Medicine, Ramathibodi Hospital (ID 09-61-59 for IgAN and ID 09-61-29 for HSPN).

\section{Consent for publication:}

not applicable

\section{Conflicts of interest:}

The authors declare no potential conflicts of interest with respect to this study.

\section{Funding:}

The authors received no financial support for this study.

\section{Acknowledgements:}

The authors would like to thank the director and staffs of Division of Nephrology, Department of pediatrics, Faculty of Medicine Ramathibodi Hospital for their cooperation and support.

\section{Author contribution:}

S.C. and K.P. designed the study. S.C, K.T., P.S., S.C., S.W. and K.P. performed the research. S.C and K.P. analyzed the data. S.C. and K.P. wrote the paper. S.C, K.T., P.S., S.C., S.W. and K.P. have read and approved the final manuscript.

\section{References}


1. Jauhola O, Ronkainen J, Koskimies O, Ala-Houhala M, Arikoski P, Holtta T, et al. Renal manifestations of Henoch-Schonlein purpura in a 6-month prospective study of 223 children. Arch Dis Child. 2010;95(11):877-82.

2. Saulsbury FT. Henoch-Schonlein purpura in children. Report of 100 patients and review of the literature. Medicine (Baltimore). 1999;78(6):395-409.

3. Pabunruang W, Treepongkaruna S, Tangnararatchakit K, Chunharas A, Phuapradit P. HenochSchonlein purpura: clinical manifestations and long-term outcomes in Thai children. J Med Assoc Thai. 2002;85 Suppl 4:S1213-8.

4. Sanders JT, Wyatt RJ. IgA nephropathy and Henoch-Schonlein purpura nephritis. Curr Opin Pediatr. 2008;20(2):163-70.

5. Calvo-Rio V, Loricera J, Martin L, Ortiz-Sanjuan F, Alvarez L, Gonzalez-Vela MC, et al. HenochSchonlein purpura nephritis and IgA nephropathy: a comparative clinical study. Clin Exp Rheumatol. 2013;31(1 Suppl 75):S45-51.

6. Kiryluk K, Moldoveanu Z, Sanders JT, Eison TM, Suzuki H, Julian BA, et al. Aberrant glycosylation of IgA1 is inherited in both pediatric IgA nephropathy and Henoch-Schonlein purpura nephritis. Kidney Int. 2011;80(1):79-87.

7. Ozen S, Pistorio A, lusan SM, Bakkaloglu A, Herlin T, Brik R, et al. EULAR/PRINTO/PRES criteria for Henoch-Schonlein purpura, childhood polyarteritis nodosa, childhood Wegener granulomatosis and childhood Takayasu arteritis: Ankara 2008. Part II: Final classification criteria. Ann Rheum Dis. 2010;69(5):798-806.

8. Kawasaki Y, Ono A, Ohara S, Suzuki Y, Suyama K, Suzuki J, et al. Henoch-Schonlein purpura nephritis in childhood: pathogenesis, prognostic factors and treatment. Fukushima J Med Sci. 2013;59(1):1526.

9. Lau KK, Suzuki H, Novak J, Wyatt RJ. Pathogenesis of Henoch-Schonlein purpura nephritis. Pediatr Nephrol. 2010;25(1):19-26.

10. Edstrom Halling S, Soderberg MP, Berg UB. Predictors of outcome in paediatric IgA nephropathy with regard to clinical and histopathological variables (Oxford classification). Nephrol Dial Transplant. 2012;27(2):715-22.

11. Hastings MC, Delos Santos NM, Wyatt RJ. Renal survival in pediatric patients with IgA nephropathy. Pediatr Nephrol. 2007;22(2):317-8.

12. Kusumoto Y, Takebayashi S, Taguchi T, Harada T, Naito S. Long-term prognosis and prognostic indices of IgA nephropathy in juvenile and in adult Japanese. Clin Nephrol. 1987;28(3):118-24.

13. Nozawa R, Suzuki J, Takahashi A, Isome M, Kawasaki Y, Suzuki S, et al. Clinicopathological features and the prognosis of IgA nephropathy in Japanese children on long-term observation. Clin Nephrol. 2005;64(3):171-9.

14. Yoshikawa $\mathrm{N}$, Ito $\mathrm{H}$, Nakamura $\mathrm{H}$. IgA nephropathy in children from Japan. Clinical and pathological features. Child Nephrol Urol. 1988;9(4):191-9. 
15. D'Amico G. Natural history of idiopathic IgA nephropathy and factors predictive of disease outcome. Seminars in Nephrology. 2004;24(3):179-96.

16. Calvo-Rio V, Hernandez JL, Ortiz-Sanjuan F, Loricera J, Palmou-Fontana N, Gonzalez-Vela MC, et al. Relapses in patients with Henoch-Schonlein purpura: Analysis of 417 patients from a single center. Medicine (Baltimore). 2016;95(28):e4217.

17. Lei WT, Tsai PL, Chu SH, Kao YH, Lin CY, Fang LC, et al. Incidence and risk factors for recurrent Henoch-Schonlein purpura in children from a 16-year nationwide database. Pediatr Rheumatol Online J. 2018;16(1):25.

18. Prais D, Amir J, Nussinovitch M. Recurrent Henoch-Schonlein purpura in children. J Clin Rheumatol. 2007;13(1):25-8.

19. Butani L, Morgenstern BZ. Long-term outcome in children after Henoch-Schonlein purpura nephritis. Clin Pediatr (Phila). 2007;46(6):505-11.

20. Coppo R, Andrulli S, Amore A, Gianoglio B, Conti G, Peruzzi L, et al. Predictors of outcome in HenochSchonlein nephritis in children and adults. Am J Kidney Dis. 2006;47(6):993-1003.

21. Scharer K, Krmar R, Querfeld U, Ruder H, Waldherr R, Schaefer F. Clinical outcome of SchonleinHenoch purpura nephritis in children. Pediatr Nephrol. 1999;13(9):816-23.

22. Flynn JT, Kaelber DC, Baker-Smith CM, Blowey D, Carroll AE, Daniels SR, et al. Clinical Practice Guideline for Screening and Management of High Blood Pressure in Children and Adolescents. Pediatrics. 2017;140(3).

23. Schwartz GJ, Munoz A, Schneider MF, Mak RH, Kaskel F, Warady BA, et al. New equations to estimate GFR in children with CKD. J Am Soc Nephrol. 2009;20(3):629-37.

24. Trimarchi H, Barratt J, Cattran DC, Cook HT, Coppo R, Haas M, et al. Oxford Classification of IgA nephropathy 2016: an update from the IgA Nephropathy Classification Working Group. Kidney International. 2017;91(5):1014-21.

25. Huang $X$, Ma L, Ren P, Wang H, Chen L, Han H, et al. Updated Oxford classification and the international study of kidney disease in children classification: application in predicting outcome of Henoch-Schonlein purpura nephritis. Diagn Pathol. 2019;14(1):40.

26. Wong N, Kang A, Mcadoo S, Cook T, Pusey C. 121. MEST-C SCORE in Adult HenochHenoch-Schonlein purpura nephritis. Rheumatology. 2019;58.

27. Counahan R, Winterborn MH, White RH, Heaton JM, Meadow SR, Bluett NH, et al. Prognosis of Henoch-Schonlein nephritis in children. Br Med J. 1977;2(6078):11-4.

28. Yang XQ, Huang YJ, Zhai WS, Ren XQ, Guo QY, Zhang X, et al. Correlation between endocapillary proliferative and nephrotic-range proteinuria in children with Henoch-Schonlein purpura nephritis. Pediatr Nephrol. 2019;34(4):663-70.

29. Inagaki K, Kaihan AB, Hachiya A, Ozeki T, Ando M, Kato S, et al. Clinical impact of endocapillary proliferation according to the Oxford classification among adults with Henoch-Schonlein purpura nephritis: a multicenter retrospective cohort study. BMC Nephrol. 2018;19(1):208. 
30. Lv J, Shi S, Xu D, Zhang H, Troyanov S, Cattran DC, et al. Evaluation of the Oxford Classification of IgA nephropathy: a systematic review and meta-analysis. Am J Kidney Dis. 2013;62(5):891-9.

31. Goldstein AR, White RH, Akuse R, Chantler C. Long-term follow-up of childhood Henoch-Schonlein nephritis. Lancet. 1992;339(8788):280-2.

32. Fu H MJ, Huang L. Higher pathological grading is associated with unfavorable outcome of HenochSchonlein purpura nephritis in children. Int J Clin Exp Pathol. 2016;9(4):4633-40.

33. Mir S, Yavascan O, Mutlubas F, Yeniay B, Sonmez F. Clinical outcome in children with HenochSchonlein nephritis. Pediatr Nephrol. 2007;22(1):64-70.

34. Bulut IK, Mir S, Sozeri B, Bulut MO, Sen S, Dincel N. Outcome results in children with IgA nephropathy: a single center experience. Int J Nephrol Renovasc Dis. 2012;5:23-8. 